\title{
Occupational health and safety in the Moroccan construction sites: preliminary diagnosis
}

\author{
Bakeli Tarik ${ }^{*}$ and Hafidi Alaoui Adil \\ Mechanics and Civil Engineering's Laboratory, Faculty of Sciences and Techniques, Abdelmalek Essaâdi University, Tangier, \\ Morocco
}

Received: 5 May 2017 / Accepted: 19 February 2018

\begin{abstract}
Managing occupational health and safety on Moroccan construction sector represents the first step for projects' success. In fact, by avoiding accidents, all the related direct and indirect costs and delays can be prevented. That leads to an important question always asked by any project manager: what are the factors responsible for accidents? How can they be avoided? Through this research, the aim is to go through these questions, to contribute in occupational health and safety principles understanding, to identify construction accidentology and risk management opportunities and to approach the case of Moroccan construction sites by an accurate diagnosis. The approach is to make researchers, managers, stakeholders and deciders aware about the criticality of construction sites health and safety situation. And, to do the first step for a scientific research project in relation with health and safety in the Moroccan construction sector. For this, the paper will study the related state of art namely about construction sites accidents causation, and will focus on Reason's 'Swiss cheese' model and its utilization for Moroccan construction sites health and safety diagnosis. The research will end with an estimation of an accidents fatality rate in the Moroccan construction sector and a benchmarking with the international rates. Finally, conclusions will be presented about the necessity of Occupational Health and Safety Management System (OHSMS) implementation, which shall cover all risk levels, and insure, at the same time, that the necessary defenses against accidents are on place.
\end{abstract}

Keywords: Construction / occupational health and safety / accident / fatality / risk / project management / construction site / Morocco / Swiss cheese model

\section{Introduction}

Recently, the Moroccan construction sector started to integrate gradually into a new approach based on the principles of sustainable development. An approach that required special consideration of working conditions, health and safety, through the elimination of accidents risk. Indeed, "an installation should not be considered sustainable if an injury or death occurred during its construction, maintenance or use" [1].

Nowadays, posting the "Number of days since the last lost time accident occurred" is not a fashion that a project manager choose to follow. In fact, this important factor affects directly and indirectly the cost and duration of projects. That makes the determination and control of factors responsible for site accidents the first step for project success. In this optic, the first part of this research will start with a literature analysis through papers, books, and articles in order to have a good reference about the

\footnotetext{
* Corresponding author: tbakeli@gmail.com
}

level how occupational health and safety is highlighted throughout the world, and point out the huge importance of managing health and safety performance in construction sites. It will be also an opportunity to focus on factors responsible for site accidents by using the Reason's model [2]. Finally, one of the most basic and important health and safety codes, developed by the International Labour Organization [3] will be presented.

Based on the Reason's Model approach [2], the second part of our research will be devoted to compare between Moroccan and international construction sites' accidents statistics, safety data and practiced standards. That will represent an accurate diagnosis of Moroccan construction sites health and safety in different levels: organisational, management and preconditions. The described situation will be confirmed, then, using an estimated fatality rate that is calculated based on the available references because of the non-accuracy of data in Morocco related to accidents statistics on construction sector. That will serve for a comparison, in term of construction accidents fatality rates, between Morocco and different countries in the 
world, and will confirm that Moroccan construction sites are not only very far from the International standards, but are also characterized by a high level of risk in term of accidents

\section{Background literature}

\subsection{Definitions}

Health and safety include the laws, rules, and principles that are intended to keep people safe from injury or disease at work and in public places [4].

Occupational health and safety (OHS or OSH) is defined as the science of the anticipation, recognition, evaluation and control of hazards arising in or from workplace that could impair the health and well-being of workers. That includes also taking into account the possible impact on the surrounding communities and the general environment [5]. In project management, it can also be named HSE: Health, Safety and Environment, in this case Environment protection is included.

Accident is defined as any unplanned event that results in injury or ill health of people, or damage or loss to property, plant, materials or the environment or a loss of a business opportunity [6].

Near Miss is an event not causing harm, but has the potential to cause injury or ill health [6].

A hazard is the potential of a substance, activity or process to cause harm [6]. In fact, Water on a staircase can constitute a hazard, because someone may slip on it, fall and hurt itself.

A risk is the likelihood of a substance, activity or process to cause harm [6]. It is a "two-part concept" which is composed of likelihoods, expressed as probabilities, frequencies or in a qualitative way, and the effect that can be described in many different ways.

Risk management is defined as a three-staged process [7]. First, identification of hazards, which are the potential of substances, activities or processes to cause harm [6]. Second, assessment of the risks related, which are hazards' likelihoods to cause harm [6]. Finally, implementation of appropriate risk controls as given by the National Institute for Occupational Safety and Health (NIOSH) in the United States through hierarchy of actions [7] shown in Figure 1.

\subsection{Factors responsible for site accidents}

Construction is commonly called industry because it concretizes projects as per design. However, a construction site cannot be managed like factory because it is constantly changing, involving many sub-contractors, and executing various works. That makes workers on site facing everyday simultaneous factors that can cause new hazards and lead to risks that can potentially cause accidents and near misses.

The state of art about the subject of construction site accidents' factors numerates, not exhaustively, project nature [8], construction method [8-10], site restriction $[10,11]$ project duration [10,12], design [13,14], subcontracting [15], Procurement system [14], training [8], client profile [8]. These factors can be grouped into five levels:

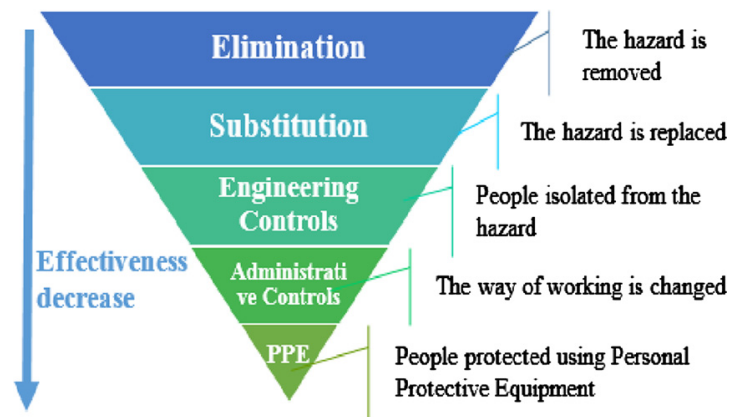

Fig. 1. Hierarchy of controls pyramid [7].

- organizational level: it includes all the factors related to decision makers, legislation, policy makers, clients, senior management of projects, designers, etc;

- management level: it includes all the factors related to production management through several departments (maintenance, human resources, operations, etc.);

- preconditions level: it is about factors and conditions linked to the level of motivation of employees, their knowledge, their training, the equipment used and the way in which things are being done;

- unsafe acts level: it is related to human comportment;

- defences level: it includes protective measures according to hazardous conditions (work at height, excavation, etc.).

On the other hand, accidents factors can be organized according to the following eight risks:

- work at height;

- lifting;

- energy isolation;

- mobile equipment;

- confined space;

- excavations;

- hazardous materials;

- electrical works.

In reality, it is very complex to understand how an accident happens on a construction site. Because it implicates understanding the interaction between the various factors in different levels. In fact, every factor can be the source of at least a hazard that can happen simultaneously with another. In this optic, many studies was conducted to develop models of accident causation, which can help to identify systems' defects and then put in place the necessary corrections.

Reason developed a model of accidents causation, known as the 'Swiss cheese' model [2], which explains deeply the combined effect of the various accident factors already seen. In fact, construction site accidents can be traced back using what Reason calls 'latent condition pathways'; they are a sort of "holes" existing on 'Swiss cheese' slices that are placed side by side as presented in Figure 2. Every slice is one of the factors levels. Indeed, the 'latent condition pathways' are, in reality, circumstances with risks and safety outcomes caused by an accident factor in the level. Reason defines the concept of accidental trajectory as being the trajectory on which each level's holes are aligned [2]. 


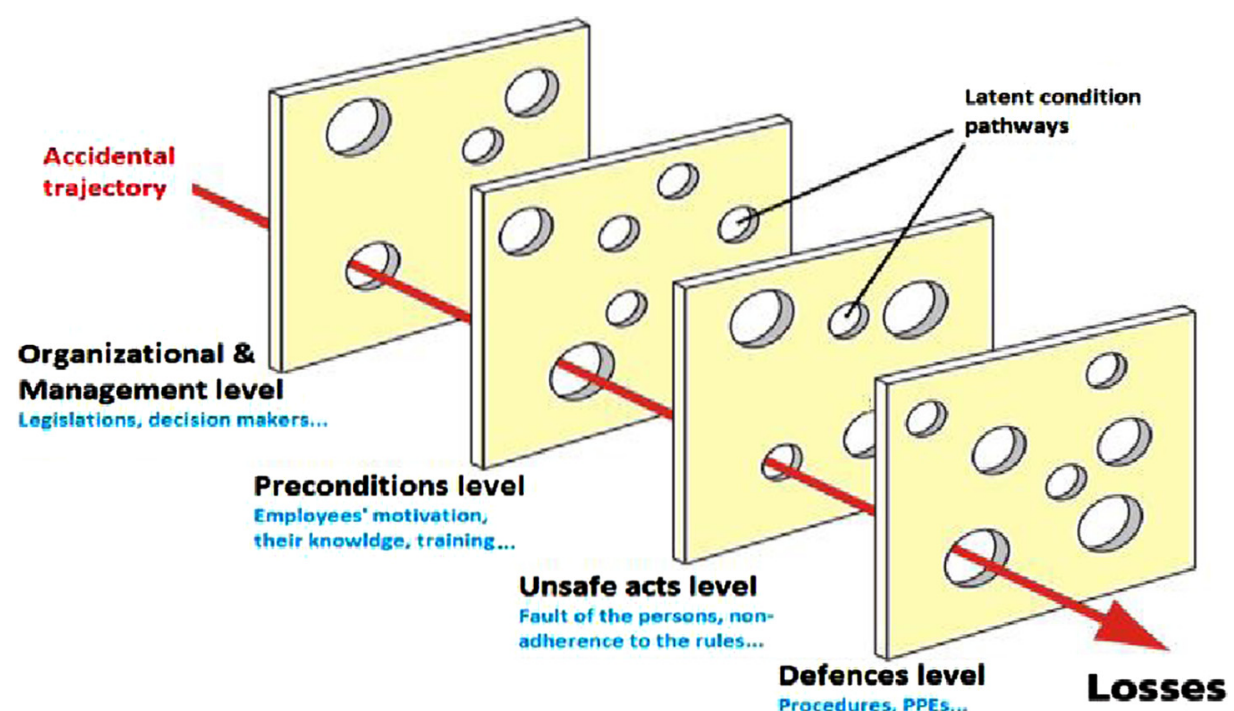

Fig. 2. Reason's 'Swiss cheese' model [2].

In the same way, the Matrix presented in Figure 3 shows that on each Reason's Model level, there are factors that can lead to accidents. If the same types of factors happen in the same time on all the levels, there is a big chance that accident occurs because accidental trajectory is systematically formed.

For example, in Figure 3, it is represented in red an accidental trajectory related to work at height risk. Indeed, an accident such as fall of height can certainly happen, if we have in the same time failures in all the following levels:

- Organizational level: design team did not make any effort to avoid work at height.

- Management level: there is no adequate material such as controlled scaffolds installed, which makes the employees climbing a structure to arrive to working zone.

- Preconditions level: employees working at height are not trained.

- Unsafe acts level: employees are not disciplined and does not believe in what the foreman says.

- Defences level: employees are not using suitable protection devices like harness.

Another example of accidental trajectory is represented in Figure 3 in green, which is related to confined space risk. Indeed, an accident related to confined space such as asphyxiation can certainly happen, if we have in the same time failures in all the following levels:

- Organizational level: lack of regulations.

- Management level: site manager does not believe that confined space is a safety risk.

- Preconditions level: site activity is ongoing without coverage or leadership (Absence of foreman, supervisors...).

- Unsafe acts level: although the employee noticed that communication device is damaged, he acceded the confined space.

- Defences level: the employee acceded to confined space without having in his own a gas mask.

In other words, and according to Reason's model, when many unsafe acts and unsafe conditions occur simultaneously which is the case of construction sites, only some of them result in accidents. This implies that if it is possible to control the unsafe acts and unsafe conditions, it will be possible to eliminate accidental trajectories. In fact, Near misses control, here, is playing an important role because it is able to give an idea about the holes which are site conditions (according to Reason's model) that are potentially about to cause accident.

Moreover, adopting Reason's model, to analyse construction sites accidents causation, allows also understanding that the number of holes in each of the levels and the wideness of each whole increase during the life cycle of the project. In fact, it is simply understandable that a project, starting with conceptual phase, passing through engineering and procurement, to continue with construction, is experiencing progressive and continuous changes, involving more resources, more contractors, and giving rise to more work, more coactivity and more design complexity. Therefore, accident factors, hazards and risks related get more and more numerous. In fact, this leads to an analogy with an important research presented by Behm which explains, according to Figure 4, that the ability to influence safety decreases significantly during the project lifecycle $[16,17]$.

To put it in a nutshell, coming back to hierarchy of controls, if project manager can decide to eliminate or substitute the risk during engineering phase that will be very difficult during construction phase. In addition, if construction management is able to put in place engineering controls during early construction phase, only administrative controls and personal protective equipment (PPE) or collective protection equipment (CPE) remain conceivable when construction is ahead.

According to the previous analyse, it is clear that accidents can be avoided in the very early stage of projects, if health and safety management is considered by the client, by decision makers, and by the designers. For that a proper risk assessment and risk management analyse shall be conducted before beginning of construction, and maintained during construction phase. 


\section{Organizational level}

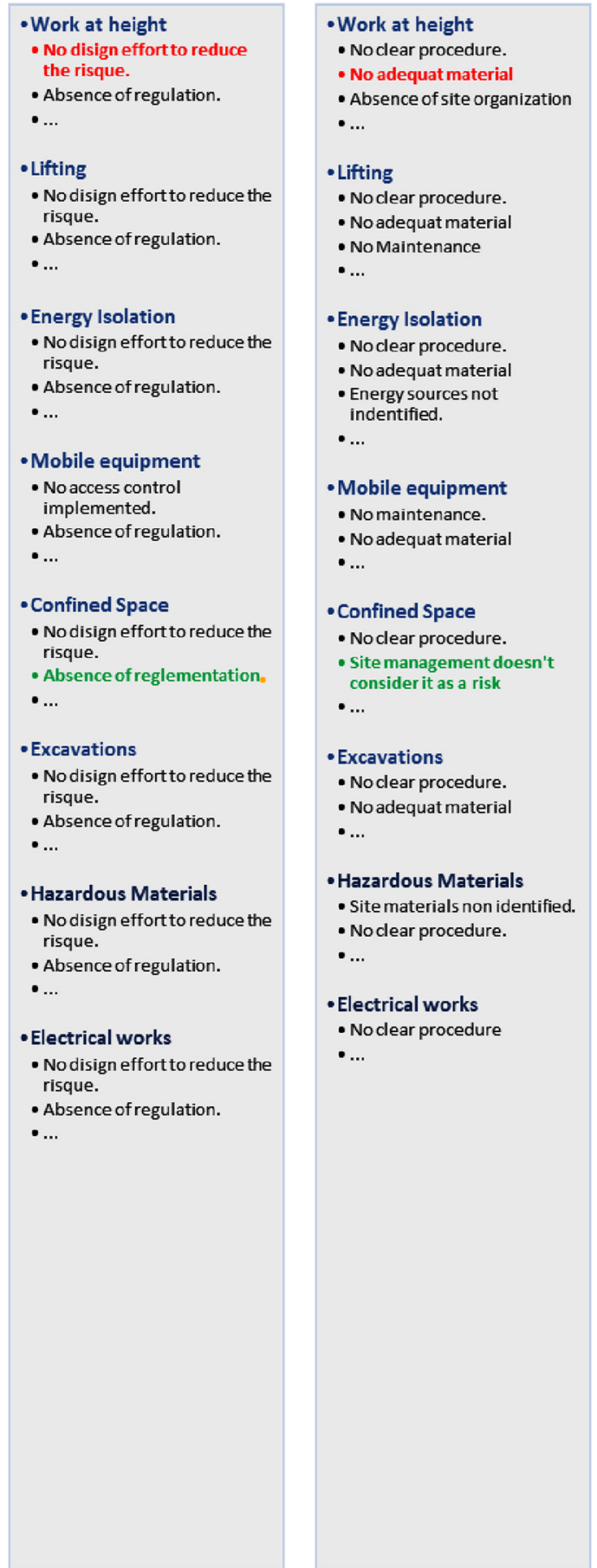

\section{Preconditions level}

\section{-Work at height}

- No site coverage/leadership.

- Employees not motivated.

- Work duration

- Work time

- No Training

-...

\section{- Lifting}

- No site coverage/leadership.

- Employees not motivated.

- Work duration

- Work time

- No Training

-...

\section{- Energy Isolation}

- No site coverage/leadership.

- Employees not motivated.

- Work duration

- Work time

- No Training

-...

- Mobile equipment

- No site coverage/leadership.

- Employees not motivated.

- Work duration

- Work time

- No Training

•...

\section{- Confined Space}

- No site coverage/leadership.

- Employees not motivated.

- Work duration

- Work time

- No Training

-...

\section{- Excavations}

- No site coverage/leadership.

- Employees not motivated.

- Work duration

- Work time

- No Training

-...

- Hazardous Materials
- No site coverage/leadership.
- Employees not motivated.
- Work duration
- Work time
- No Training
-...
- Electrical works
- No site coverage/leadership.
- Employees not motivated.
- Work duration
- Work time
- No Training
-...

\section{Unsafe acts level}

-Work at height

- Employees without

discipline

- Employees over confident

- Human error

\section{- Lifting}

- Crane driver over confident

- Slings not inspected

- Error og rigger

\section{- Energy Isolation}

- Lock-out/Tag-out procedure

not applied

- Employees over confident

- Mobile equipment

- Driver notcareful

- Human error

- Absence of Flag man

- Drugs and alcohol

-...

- Confined Space

- Employees over confident

- Absence of watch man

- Communication material

damaged

\section{- Excavations}

- Employees inqualified

- Human error

- No excavation permit

-...

- Hazardous Materials

- Unknown used materials

- Humanerror

- lack of discipline

-...

- Electrical works

- Employees over confident

- Humanerror

- suitable material not used

-...
Defences level

-Work at height

- No barricads

- No harness

- NoPPES

-...

- Lifting

- No barricads

- NoPPEs

$\bullet .$.

- Energy Isolation

- No lack-out/tag-out devices

- NoPPEs

-...

- Mobile equipment

- No Barricads

- NoPPEs

- Safety belt not used

-...

- Confined Space

- No gas protection devices

- No PPES...

- No barricads

-...

- Excavations

- No barricads

- NoPPES

-...

- Hazardous Materials

- NoPPEs

-...

\section{- Electrical works}

- NoPPES

- No collection protection

devices

-...

Fig. 3. Reasons's Model Matrix representation: accidents factors levels.

\subsection{The code of practice on the provision of health and safety items on construction sites}

ILO produced in 1992 The Code of practice on health and safety on construction site [3] with a view to provide guidelines to its members in the implementation of the health and safety practices on construction sites for all workers. That is by giving necessary guidance on a technical, administrative and legal framework for the duty-holders to comply with their legal obligations in protecting employees' health and safety and all who can be affected nearby. Of course, that gave birth to different legislations and regulations in term of occupational health and safety that is presented in Table 1.

In short, we present the way some countries have reacted toward the establishment of references for health and safety prevention and organisms to insure their necessary promotion. 


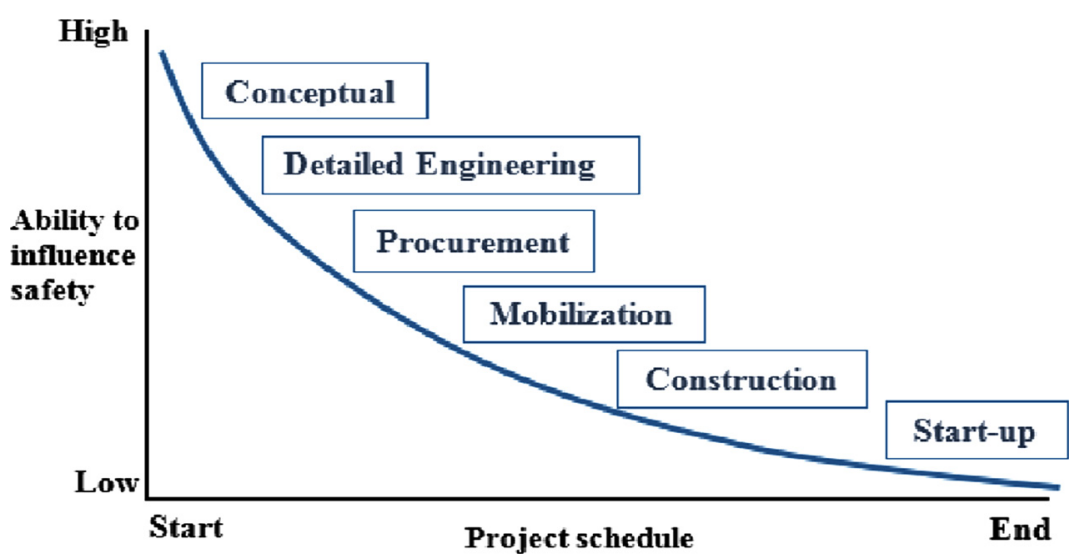

Fig. 4. Project time/Safety influence curve [16].

Table 1. OHS organisms \& regulations by countries.

\begin{tabular}{|c|c|c|}
\hline Countries & Organisms & Legislations, regulations, codes \\
\hline European Union & European agency for safety and health at work & EUOSH directives \\
\hline UK & Health and safety executive (HSE) & $\begin{array}{l}\text { Health and safety at work etc. Act } 1974 \\
\text { (HASAWA) }\end{array}$ \\
\hline USA & $\begin{array}{l}\text { Occupational safety and health administration } \\
\text { (OSHA) }\end{array}$ & Occupational safety and health act, 1970 \\
\hline Australia & Safe work Australia (SWA) & Commonwealth work health and safety act, 2011 \\
\hline Canada & $\begin{array}{l}\text { Canadian centre for occupational health } \\
\text { and safety (CCOHS) }\end{array}$ & Provincial or federal labour codes \\
\hline China & Ministry of Health & Work safety Act, 2002 \\
\hline
\end{tabular}

\section{Comparison between Moroccan and international construction practices in term of health and safety}

Thanks to its proactive policy of improving the business climate and the aim to position itself as a platform for access to African markets, Morocco is undergoing a major development and witnessing a huge construction boom in public sector, infrastructure projects, and investments. In parallel to this growth, the situation of occupational health and safety should have the same speed. Actually, it is believed that the integration of safety and health measures into construction projects and the reduction of the number of accidents can contribute significantly to their final cost, and efficiency. That is through, for instance, the reduction of direct costs and delays caused by work stoppages after accidents, and indirect costs caused by affected companies reputation and insurance fees.

Hence, the objective of this part of the research is to compare between Moroccan and International construction practices in term of health and safety. In the meantime, Reason's model approach will be followed in order to have an accurate diagnostic of the Moroccan construction sites health and safety situation and challenges.

\subsection{Moroccan construction sites organization level}

The first remark on Moroccan construction sites organization is the absence of a law that controls construction activity. In fact, the text of law 66-12 of August 25, 2016 [18], took a very long time to be developed and voted. Before this date, the situation was, and continues to be, if the law is not strictly applied, "anarchic".

Moreover, the client is having a big part of responsibility, being the only one who decides about the project policy. In fact, being the one who pays, he is the first to choose how the project will be designed, who will take over the project leadership, and how it will be executed. That makes health and safety, seen as a loss of time or a "luxury", and the last thing that client and project leaders think about. The same situation is reflected on constructors and sub-contractors that are obliged to follow clients and project leaders policies to be able to get projects and resist to the high competitively that is clearly noticed in the Moroccan construction market.

In term of legislations, the evolution of actions related to occupational health and safety in Morocco was analysed, and compared with other countries. This is summarized on the time line of Figure 5. Some of the deducted conclusions can be:

- the Moroccan efforts in term of legislations, compared to the International, took a long time and adopted a special approach. In fact, Morocco choose 

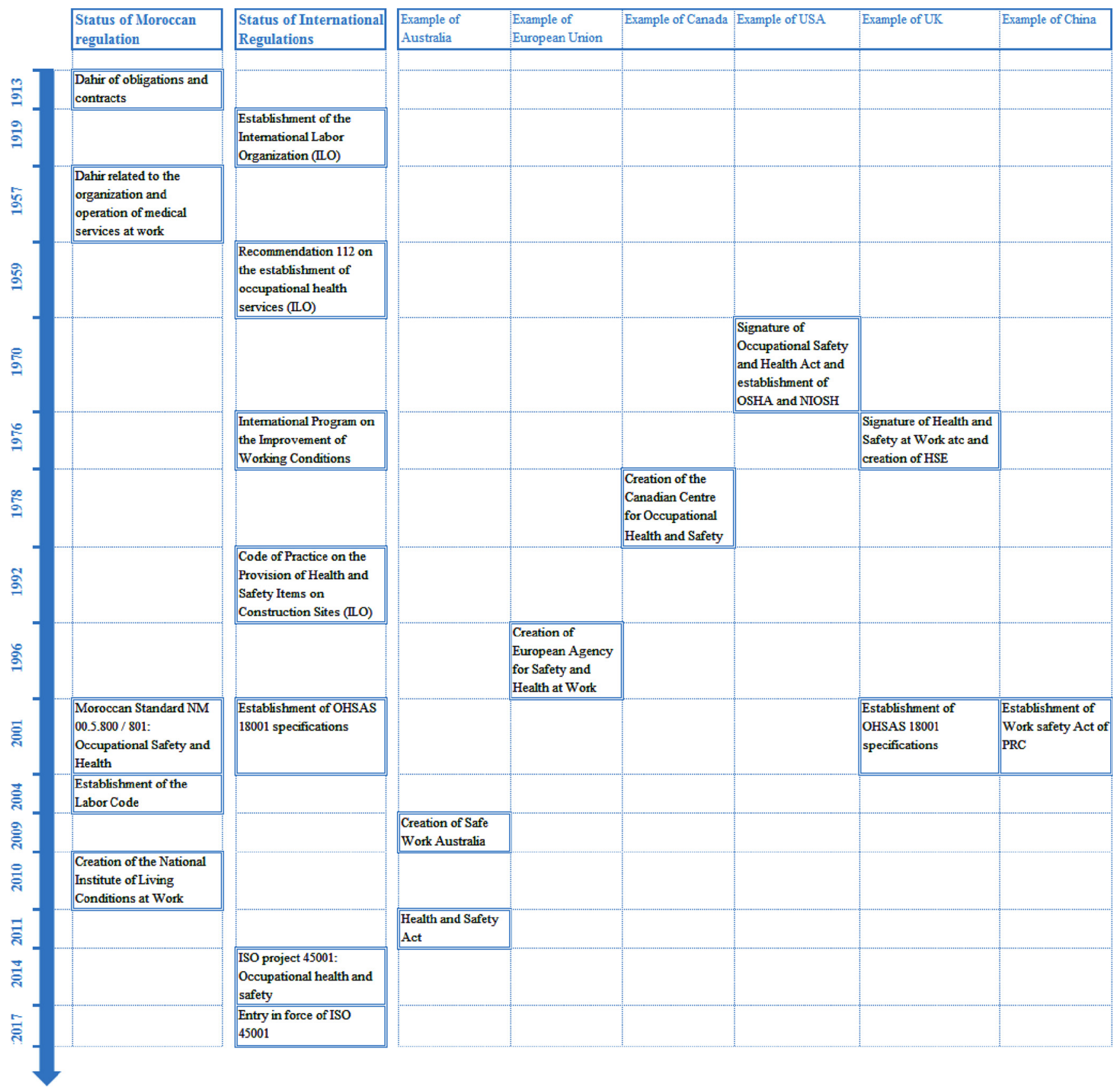

Fig. 5. Time evolution of Moroccan and International OHS regislations.

to start with the production of standards known as NM 00.5.800/801 which are a "copy-past" of other standards $[19,20]$, with no legal authority, and no organism to insure its application. It would be rather if the example of many other countries were followed through the creation of institutions responsible of putting in place human, medical, scientific, documentary, technical and legal resources able to enhance safety and health at work;

- Australia took also a long time to react toward occupational health and safety. However, it made a significant improvement in term of safety legislation.
To sum up, it is clear according to this part of the research that the organization level of Moroccan construction sites is backward compared to the International. It contains also many gaps susceptible to be 'latent condition pathways' for accidents according to the Reason's Model.

\subsection{Moroccan construction sites management and precondition levels}

The unsafe acts and conditions arise from the basis of Moroccan construction sites' structure. On the one hand, it is noted that almost all these projects consists of a 
Table 2. Comparaison between Moroccan and International construction sites fatality rates.

\begin{tabular}{|c|c|c|c|}
\hline Countries & $\begin{array}{c}\text { Fatality rate (per } \\
100000 \text { employees per year) }\end{array}$ & References & $\begin{array}{c}\text { How high is Moroccan } \\
\text { fatality rate }\end{array}$ \\
\hline UK & 1.62 & Health and safety executive (HSE), 2015 [25] & $\times 13.8$ \\
\hline USA & 10.10 & U.S. Bureau of Labor Statistics, 2017 [26] & $\times 2.21$ \\
\hline Australia & 3.29 & Safe work Australia (SWA), 2013 [27] & $\times 6.8$ \\
\hline Irland & 9.80 & Health and safety authority, 2014 [28] & $\times 4.1$ \\
\hline France & 9.34 & $\begin{array}{l}\text { Institut national de recherche et } \\
\text { de sécurité, } 2014[29]\end{array}$ & $\times 2.4$ \\
\hline Europe & 21.00 & European Commission, 2014 [30] & $\times 1.06$ \\
\hline
\end{tabular}

heterogeneous workforce, whose profile varies between skilled and unskilled workers. They are never sure to keep their jobs at the end of construction activity. This contributes to their precariousness and does not allow them to become professional and thus to be trained in matters of safety. On the other hand, and although the site is equipped with safety shoes, harnesses or helmets, workers are reluctant to use them because of their unconsciousness, their fatalism and their misunderstanding of the role of personal protective equipment. In addition, the cost of safety is not often taken into account when concluding contracts. This makes the presence of PPE on site very rare.

Other factors explain the enormous risk of accidents in construction sites. Indeed, it is noteworthy the neglect of safety standards during construction activities. That is because the OHS regulation in Morocco is very recent, and the authorities for its implementation are absent, despite the existence of three police forces (District prefecture, communes and urban agencies) whose missions are to inspect construction sites and to verbalize in case of violation. In addition, the absence of statistics, the lack of involvement of business leaders, the concern for productivity and schedule, and the decentralization of on-site productivity management are other factors that makes the situation worst.

In brief, it is clear that the management and preconditions levels of Moroccan construction sites are full of gaps that are likely to be 'latent condition pathways' for accidents according to the Reason's Model. In addition, the profile of the workforce makes also the unsafe acts level in the same situation. Then, the risk of occurrence of accidents is very high, and linked directly to the defences that may be present on site (PPE, strict safety management, procedures...). Such defences are also very rare on Moroccan construction sites and are even not taken into consideration.

\subsection{Moroccan construction sites accidents rates}

The latest official declarations of Houcine El Ouardi, Moroccan Minister of Health, on December 18, 2013 unveiled a site work related fatality rate in Morocco of 47.8 per 100000 employees per year [21]. A rate that can not be confirmed because of non-accuracy of data in Morocco related to accidents statistics on construction sector.

Through this paragraph, a referenced estimation of Moroccan construction sites fatality rate will be discovered.

First, the following equation will be used:

\section{Fatality rate}

$$
=\frac{\text { Fatal accidents }(\text { Const. Sector })}{\text { Total employment (Const. Sector) }} \times 100000 \text {. }
$$

The ILO statistics, putting Morocco in the region of Low- and middle-income countries of the African region (AFRO), estimates that $25 \%$ of the total work related fatalities is happening in construction sites [22]. Then, the previous equation becomes:

\section{Fatality rate}

$$
=\frac{0.25 \times \text { Fatal accidents }(\text { Global })}{\text { Total employment }(\text { Const. Sector })} \times 100000 .
$$

The Moroccan Haut-Commissariat au plan, on its note on the labor market in Morocco of between 2000 and 2014, confirmed that $9.3 \%$ of global total employment are in Construction sector [23]. That means:

Fatality rate

$$
=\frac{0.25 \times \text { Fatal accidents }(\text { Global })}{0.093 \times \text { Total employment }(\text { Global })} \times 100000 .
$$

Then,

Fatality rate $=2.69 \times$ Fatality rate $($ Global $)$.

The most recent available data about Moroccan global work related fatality rate exists in a Dissertation of Pardee Rand Graduate School. Indeed, it estimates the Moroccan Global Fatality rate in 2013 to 8.3 fatal accidents per 100000 employees per year [24]. That gives for the 


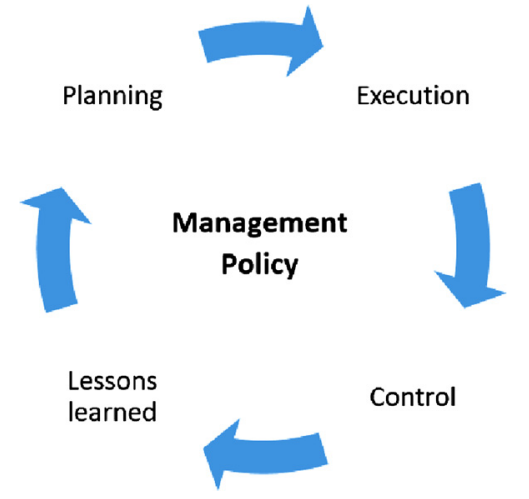

Fig. 6. PDCA cycle applied to Occupational health and safety management.

Moroccan case, in 2013, an estimation of 22.33 fatal construction sites accidents per 100000 employees per year.

This rate is compared with rates from different regions in the world and seems to be extremely high according to Table 2 .

Moreover, construction sites fatalities' rates are only the tip of an iceberg, the same analysis can show that the rates of major injuries and lost time accidents are having the same tendency. However, what makes the analysis very difficult for the Moroccan case is the non-availability of standardized statistics and accidents records on construction sites.

Finally, the National institute of living conditions at work (INCVT), which is a, recently created, state institution responsible for the implementation of regulatory measures in order to strengthen safety in Moroccan workplaces, confirms this situation. In fact, according to their last report issued after the EU-North African seminary about strategies for safety and health at work, in 2012 only, 5600 construction site accidents were registered and the cost of one accident in Morocco varies between 2000 and $20000 \mathrm{MDH}$ [31].

\section{Conclusion}

All in all, the literature review that was carried out in this paper has shown that, more the international efforts on construction sites occupational health and safety were important, less the work on health and safety in Morocco has been undertaken. Besides, what makes the situation worst is the lack of accurate data to support eventual serious diagnosis. In the other side, and based on the Reason's model, it is obvious that, at all the levels, there are dangerous gaps that can make, at any time; the Moroccan construction sites a scene of serious accidents. Hence, it is high time to work on an Occupational health and safety management system (OHSMS), which shall cover all the levels seen previously, and insure, at the same time, that the necessary defences are implemented.
One of the ways that would allow to design such a OHSMS can start with the Shewart-Deming cycle, or PDCA cycle (Plan, Do, Check and Act) [32]. Indeed, an analogy can be developped with project management quality approach for managing Health and Safety on site, by working on the 4 following components:

- planning: by focusing on risk analysis, work organisation, staffing plan, risk controls;

- execution: by studying method statements, allocating suitable material for work, insuring site management, and putting in place the necessary human and material resources for a safe work;

- control: by insuring a continuous site supervision, checking the execution of work as per contractual safety specifications, method statements and risk analysis action plans;

- lessons learned: By avoiding that, detected failures and non-conformities be repeated and capitalizing for the rest of the project and next projects.

However, safety management actions being, in general, not billed, not a deliverable, and not totally regulated, its implementation shall start with decision makers' policy. That policy shall include necessarily clear engagements and objectives related to Occupational health and safety and shall identify the norms and regulations that will be followed on site. That why, for Occupational health and safety management, it is necessary to add Management Policy to Shewart-Deming wheel, and to place it in the center of the cycle, as presented in Figure 6 , because it is exactly the center of any approach related to Health and safety management and the basis of all subsequent actions.

\section{References}

1. J. Reason, Managing the Risks of Organizational Accidents (Ashgate, Aldershot, 1997)

2. J. Gambatese, Making Green Safe, PtD in Motion, p. 8, Juillet 2009

3. ILO, The Code of Practice on the Provision of Health and Safety (International Labour Organization, Geneva, Switzerland, 1992).

4. Cambridge Dictionary, «www.dictionary.cambridge.org, [En ligne]. Available: http://dictionary.cambridge.org/dictio nary/english/health-and-safety. [Accès le 0902 2017]

5. B.O. Alli, Fundamental Principles of Occupational Health and Safety (ILO, Geneva, 2008)

6. H. Noni, An exploratory study of meanings of risk control for long term and acute effect occupational health and safety risk in small business construction firms, J. Saf. Res. 30, 61-71 (1999)

7. HSE, An Analysis of the Significant Causes of Fatal and Major Injuries in Construction in Scotland (Health and Safety Executive, Glasgow, 2006)

8. A. Gibb, Standardization and pre-assembly - distinguishing myth from reality using case study research, Constr. Manag. Econ. 19, 307-315 (2001)

9. S.A. Hide et al, Causal Factors in Construction Accidents (Health and Safety Executive, Leicestershire, 2003)

10. P. Brabrazon, A. Tipping, J. Jones, Construction Health and Safety for the New Millennium (Health and Safety Executive, UK, 2000) 
11. C. Mayhew, M. Quinlan, Subcontracting and occupational health and safety in the residential building industry, Ind. Relat. J. 28, 192-205 (1997)

12. H. Lingard, P. Pirzadeh, J. Harley, N. Blismas, R. Wakefield, Safety in Design (RMIT University, Australia, 2014) http://www.rmit.edu.au/research/health-safety-research

13. S. Charnovitz, The Construction Industry in the TwentyFirst Century: Its Image, Employment Prospects and Skill Requirements (ILO, Geneva, 2001)

14. M. Behm, Linking construction fatalities to the design for construction safety concept, Saf. Sci. 43, 589-611 (2005)

15. M. Behm, Establishing the Link between Construction Fatalities and Disabling Injuries and the Design for Construction Safety Concept, Ph.D. dissertation, Oregon State University, 2004

16. J.A. Gambatese, J.W. Mroszczyk, ASSE Professional Development Conference and Exposition, Designing for construction worker safety, American Society of Safety Engineers, 2006, p. 7, https://www.onepetro.org/conference-paper/ASSE-06-750

17. Ministère de l'Urbanisme et de l'Aménagement du Territoire - Maroc, Loi 66-12, Bulletin Officiel, 2582016

18. IMANOR, NM 00.5.801: Systèmes de management de la santé et de la sécurité au travail - Exigences, IMANOR, 2001

19. IMANOR, NM 00.5.800: Systèmes de management de santé et de sécurité au travail - Guide, IMANOR, 2001

20. MEDIA24, Ministre de la Santé Marocain, chez 3e journée inter-entreprises de santé au travail sous le thème, santé au travail, risques émergents et enjeux, Casablanca, 2013

21. Bureau of Labor Statistics, www.bls.gov, United States Department of Labor, 2014. [En ligne]. Available: https:// www.bls.gov/iif/cfoi_revised14.htm. [Accès le 92 2017]

22. Moroccan Haut-Commissariat au plan, Note sur le marché du travail au Maroc entre 2000 et 2014, Rabat, 2014
23. U. Kharel, The Global Epidemic of Occupational Injuries: Counts, Costs, and Compensation (RAND Corporation, Santa Monica, Calif., 2016)

24. G.K. Lim, S.L. Lim, Global Estimates of Occupational Accidents and Work-related Illnesses (Tampere University of Technology, Tampere, 2014)

25. HSE, Health and Safety Executive, 2015. [En ligne] Available: http://www.hse.gov.uk/statistics/tables/index. htm. [Accès le 92 2017]

26. Bureau of Labor Statistics, United States Department of Labor, 2016. [En ligne]. Available: https://www.bls.gov/iif/ oshwc/cfoi/cfch0015.pdf [Accès le 132 2018]

27. Safe Work Australia, Safe Work Australia, 2013. [En ligne]. Available: http://www.safeworkaustralia.gov.au/sites/ SWA/about/Publications/Documents/926/fatalities-in-con struction.pdf. [Accès le 92 2017]

28. Health and Safety Authority, Health and Safety Authority, 2014. [En ligne]. Available: http://www.hsa.ie/eng/ Publications_and_Forms/Publications/Corporate/ HSA_Statistics_Report_2013-2014. pdf. [Accès le 92 2017]

29. INRS, Institut national de recherche et de sécurité, 2014. [En ligne]. Available: www.inrs.fr/actualites/statistiques-BTP2014.html. [Accès le 182 2017]

30. European Commission, Eurostat - Statistics explained, 2014. [En ligne]. Available: http://ec.europa.eu/eurostat/ statistics-explained/index.php/Accidents_at_work_statis tics [Accès le 132 2018]

31. A.E. Kholti, SANTÉ \& SÉCURITÉ AU TRAVAIL AU MAROC, chez Séminaire EU-Afrique du Nord - Stratégies pour la sécurité et la santé au travail, 2015

32. J.-C. Corbel, MANAGEMENT DE PROJET: Fondamentaux - Méthodes - Outils, Éditions d'Organisation, 2003

Cite this article as: Bakeli Tarik, Hafidi Alaoui Adil, Occupational health and safety in the Moroccan construction sites: preliminary diagnosis, Int. J. Metrol. Qual. Eng. 9, 6 (2018) 